\title{
The Creation of OpenCourseWare at MIT
}

\author{
Hal Abelson, Massachusetts Institute of Technology*
}

\begin{abstract}
This paper traces the genesis of the MIT OpenCourseWare project from its initial strategic precursors in 1999 and 2000, through its launch in 2001 and its subsequent evolution. The story told here illuminates the interplay among institutional leadership, and strategic planning, and with university culture in launching major educational technology enterprises. It also shows how initiatives can evolve in unexpected ways, and can even surpass their initial goals. The paper concludes with an overview of challenges facing OpenCourseWare in moving from the end of its production ramp-up and towards sustainability. ${ }^{1}$
\end{abstract}

In 1999, the Massachusetts Institute of Technology began to initiate the most extensive array of coordinated educational technology innovations it had embarked on in a quarter century. Activities ranged from single-semester experiments by individual faculty members and small student groups, to sweeping institutional commitments such as the overhaul of freshman physics, which abolished traditional lectures from what was then MIT's largest lecture subject. ${ }^{2}$ The signature innovation of this entire period has been MIT OpenCourseWare (OCW), a visionary commitment by the Institute to publish the materials from all MIT undergraduate and graduate subjects freely and openly on the Web for permanent worldwide use. Launched in the spring of 2001, MIT OpenCourseWare currently publishes content for more than 1600 MIT subjects. The OCW web site hosted more than 1.5 million visits in January 2007 - more than two million if one includes the affiliated sites around the world that host mirrors and translations of the MIT material. ${ }^{3}$

In February 2005, OpenCourseWare formally moved beyond MIT with the inauguration of the OCW Consortium. Less that a year later, the Consortium includes more than 100 universities and other member organizations supporting the open

\footnotetext{
* The final version of this preprint appears in the Journal of Science Education and Technology, May 2007.

${ }^{1}$ The early phase of OpenCourseWare is also discussed by Steve Lerman and Shigeru Miyagawa in "Open Course Ware: A Case Study in Institutional Decision Making," Academe Online, vol. 88, no. 5, Sept.-Oct. 2002, at <http://www.aaup.org/publications/Academe/2002/02so/02soler.htm>, visited June 27, 2006.

${ }^{2}$ See Dori, Yuhudit Judi and John Belcher (2004) "How Does Technology-Enabled Active Learning Affect Undergraduate Students' Understanding of Electromagnetism Concepts?” The Journal of the Learning Sciences, 14 (2), 2004. Also J. Dori, J. Belcher, M. Bessette, M. Danziger, A. McKinney, and E. Hult, "Technology for Active Learning." Materials Today, December 2003, pp. 44-49.

${ }^{3}$ A "visit" here, in contrast to a "hit," refers to a sequence of accesses to the OCW web site, separated in time from the next visit by at least 30 minutes. A single visit thus typically consists of multiple hits.
} 
publication of materials from more than 3000 courses. ${ }^{4}$ The OpenCourseWare initiative has become emblematic of the movement for "Open Educational Resources," a term first adopted at the UNESCO 2002 Forum on the Impact of Open Courseware for Higher Education in Developing Countries, as an expression of the participants' wish "to develop together a universal educational resource available for the whole of humanity."

Yet OpenCourseWare was not born with such lofty ambitions. It began as a purely MIT-centric initiative. At its very beginning, it was not even about open course materials. This paper traces the genesis of OCW from its initial strategic precursors in 1999 and 2000, through its launch in 2001 and its subsequent evolution. The story told here illuminates the interplay among institutional leadership, and strategic planning, and with university culture in launching major educational technology enterprises. It also shows how initiatives can evolve in unexpected ways, and can even surpass their initial goals. Even so, entering 2007, MIT faces challenges in moving OpenCourseWare from the end of its production ramp-up and towards sustainability. ${ }^{6}$

\section{Strategic precursors (Fall 1999 - Winter 2000)}

OpenCourseWare emerged from a cluster of strategic activities overseen by the MIT Council on Educational Technology, a group whose charter is "to provide strategic guidance and oversight of MIT efforts to develop an infrastructure and initiatives for the application of technology to education." The goal of the Council is "to enhance the quality of MIT education through appropriate application of technology, to both oncampus life and learning and through distance learning." ${ }^{\prime \prime}$ The Council's functions include coordinating the allocation of central funding for educational technology initiatives, monitoring the effectiveness of ongoing programs, and setting priorities for investments in new educational technology infrastructure.

The Council was launched in the fall of 1999, largely through the initiative of Provost Robert Brown, who served as co-chair. ${ }^{8}$ Brown also chaired the Council's Strategy Group, which was charged with developing and maintaining a strategic framework for MIT-wide initiatives in educational technology, including establishing priorities for initiating programs. One of the Strategy Group's first decisions upon the

\footnotetext{
${ }^{4}$ These statistics are based on the monthly reports form MIT OpenCourseWare and the OpenCourseWare Consortium. The MIT OpenCourseWare web site is at $<\mathrm{http}: / /$ ocw.mit.edu $>$ and the consortium web site is at $<$ http://www.ocwconsortium.org/>.

${ }^{5}$ Final Report of the Forum on the Impact of Open Courseware for Higher Education in Developing Countries, UNESCO, Paris, July, 2002, document code CI.2002/CONF.803/CLD.1, at $<$ http://unesdoc.unesco.org/ulis/cgi-bin/ulis.pl?catno=128515>, visited October 10, 2006.

${ }^{6}$ MIT's decision to launch OpenCourseWare is also discussed by Steve Lerman and Shigeru Miyagawa in "Open Course Ware: A Case Study in Institutional Decision Making," Academe Online, vol. 88, no. 5, Sept.-Oct. 2002, at <http://www.aaup.org/publications/Academe/2002/02so/02soler.htm>, visited June 27, 2006.

7 "Provost announces formation of council on educational technology", MIT News Office, September 29, 1999, at <http://web.mit.edu/newsoffice/1999/council-0929.html>, visited March 19, 2006.
}

${ }^{8}$ Brown resigned as MIT Provost in September 2005, to assume the presidency of Boston University. 
formation of the Council was to work with an outside consulting firm, and in December, it selected McKinsey and Company to lead a study aimed at defining and evaluating MIT's options in the changing educational environment of the Internet. The work was to be carried out by a joint McKinsey-MIT team over the next three months, culminating in a report to the Educational Technology Council in April.

December 1999 was still full-fledged dot-com euphoria time, and the possibilities for a world-leading university like MIT seemed limitless - and daunting. Three years earlier, the eminent management consultant Peter Drucker had famously predicted that "thirty years from now the big university campuses will be relics ... The college won't survive as a residential institution," "9 and murmurs about the displacement of the traditional university rustled throughout the halls of academe. Flocks of hopeful dot-com startup suitors courted leading universities, offering to usher them - and their famous brands - into the lucrative world of Internet distance education. Some of these ventures were already making offers to MIT: UNext (which had begun to work with Stanford, Chicago, Columbia, and CMU), Pensare (working with Harvard Business School and the Wharton School of Commerce), and Caliber Learning (working with Georgetown, USC, Wharton, and Johns Hopkins). Other institutions were launching commercial ventures of their own: the Princeton-Oxford-Stanford-Yale \$12M "POSY Alliance" for Lifelong Learning to create distance education courses for alumni, Columbia's Fathom Knowledge Network for online learning, and Cornell's eCornell on-line professional development courses.

In this gold-rush atmosphere MIT, which after all was a leading technology institution, seemed like a disorganized straggler. At an early meeting of the MITMcKinsey team, one consultant sketched an image depicting various ongoing MIT initiatives - collaborations with National University of Singapore and Cambridge University, initiatives with Microsoft and Hewlett-Packard, and others - as a gaggle of sailboats drifting whichever way, rather than moving in formation.

The team's first activity was to conduct interviews on campus to better understand how the community might react to various project proposals. The result, as reported by the consultants, was a list of MIT "core beliefs":

- MIT has a dual research and educational mission: Faculty time is the limiting resource in innovation. At the same time research and teaching should continue to be linked and synergistic. Any expansion of the faculty would need to adhere to MIT's relatively tight definition of faculty, in which all faculty participate in teaching, research and service.

- MIT's role as a residential institution is paramount: Improving the quality of the on-campus experience is a high priority - maintaining the quality of the MIT community is critical, and strengthening it is desirable. Intimate student/faculty interactions should be preserved and enhanced

\footnotetext{
${ }^{9}$ Quoted in Robert Lenzer and Stephen Johnson, "Seeing things as they really are," Forbes, March 10, 1997.
} 
- MIT is unwilling to compromise on student standards for enrollment in degree programs. MIT's core advantages are its reputation and its ability to bring together world-class students and faculty

This list was hardly surprising to the MIT members of the team. But as the consultants noted, the emphasis on a single-class faculty, the links between teaching and research, and the unwillingness to compromise on standards meant that proposals for distance education programs, where students don't generally participate in research, and which are often taught by non-regular faculty, would be greeted with intense skepticism, if not outright hostility.

The team also sketched a few broad themes for how MIT might take advantage of Internet opportunities, each one identified by a caricatured label:

- "Forever-tech": Create a lifelong extended community of faculty, staff, students, and alumni who interact both on and off campus, and establish a continuing education program for alumni to pursue advanced degrees and update their skills.

- "Ed-tech:" Establish a leading center for research and technological innovation in education, and use MIT as an experimental lab to test new educational technology.

- "Flex-tech": Offer a flexible and more customized educational program, including off-campus learning, to both enhance the educational experience and offer MIT education to students who would not attend a standard 4-year residential program.

- “Global-tech": Create a degree-granting program with physical presence at multiple locations to reach MIT-quality students who normally would not come to MIT.

- “Tech-tech": Become a leading educational provider to MIT's corporate partners, delivering customized courses based on MIT's strengths in inter-disciplinary knowledge and technological development.

- "Venture-tech": Create a joint venture with other top universities to support and market on-line continuing education courses to a mass market

In February 2000, the Council's Strategy Group met to review these options and to pick directions for the consulting team to flesh out. The result was to place highest priority on Forever-tech, with the Strategy Group citing the benefit to the MIT community. Ed-tech was second, again because of its potential benefit to MIT's current educational mission. Flex-tech was an intriguing third possibility, although it should not be pursued as a priority in itself, rather as a part of forever-tech. For Global-tech the Strategy group felt that MIT should be learning from its ongoing collaborations with Singapore and Cambridge, but was not ready for a more comprehensive effort. For Techtech, there were several individual programs that addressed opportunities with particular industry partner, and there didn't appear to be a need for a centralized effort. For Venture-tech, there didn't seem to be much support anywhere in the MIT community. As Chancellor Larry Bacow remarked, "MIT is not a profit-making institution." 
The options presented posed the classic industry strategic choice of "move into new markers" versus "focus on core constituencies." In MIT's case, this amounted to, on the one hand, increasing the Institute's reach and influence, expanding MIT education globally to top-tier students, and creating educational offerings for the corporate and mass markets; versus improving the experience "at home," enhancing the quality of MIT's current education, and engaging and leveraging the MIT community. Given these alternatives, the strategy group opted clearly for "core competencies."

\section{From Forever-tech to OpenCourseWare (Spring - Fall 2000)}

Taking its cue from the February Strategy Group meeting, the MIT-McKinsey team spent the next three months outlining a few specific initiatives to consider for implementation: creating a research program in educational technology, starting a cluster of activities technology to add flexibility in the undergraduate program, and harnessing technology to enhance connections to the alumni community. But the recommendation that garnered the most interest was "Lifelong Learning", a proposal for moving ahead on the forevertech theme. In the vision of the team's April 2000 report to the Educational Technology Council:

MIT will be a valued source of education for members of its community throughout their lives. This includes knowledge update courses designed for MIT alumni and others with a solid technical education, as well as more extended offerings, such as mid-career admission to postgraduate degree programs. Programs will involve both on-campus and on-line elements, and will be adapted to the needs of working professionals.

As a near-term step, the report proposed "Knowledge Updates" - mini-courses and current hot issues and emerging fields, with content based on MIT's strengths in technical and interdisciplinary studies. These would be delivered largely on-line, but there could be on-campus elements as well.

In response, the Council chartered a Lifelong Learning summer study team to plan “Knowledge Updates@MIT", a project that would proceed as sketched in the MITMcKinsey report. The study team was asked to recommend an organizational structure for the operation, conduct a marketing study and analysis, and draw up an implementation plan.

The Knowledge Updates program would be authorized to request up to $\$ 2 \mathrm{M}$ in startup funding, but it would have to be completely self-funding after the first two years. In the words of summer study team's charter "This plan should be presented to the MIT Educational Technology Council and the MIT Administration early in September, with the presumption that it will be approved for immediate implementation."10 The study would be sponsored by the Provost together with Engineering Dean Tom Magnanti and Sloan School Dean Richard Schmalensee, and it would be led by Associate Dean of Engineering Dick Yue. To help drive the analysis, the Council had arranged for the work

\footnotetext{
${ }^{10}$ Unpublished memo from Hal Abelson and Helen Samuels to the MIT Educational Technology Council, May 2000.
} 
to again be done with a professional consulting group, this time from Booz Allen Hamilton.

The summer work was an intense effort in analysis and business planning, which drew heavily on the Booz Allen group's expertise in those areas. The team surveyed 2,500 MIT alumni on their attitudes towards continuing education. They interviewed 50 external organizations - corporations, government agencies, universities, and e-learning companies. They surveyed all members of the MIT faculty and conducted 50 individual follow-up interviews. They analyzed the capabilities of seven internal MIT organizations to deliver on various aspects of the knowledge update effort. They developed detailed financial models for ten different scenarios, each with sensitivity analyses and implementation plans.

The upshot of the analysis was that a financially viable Knowledge Updates program seemed achievable in the near term, and that it could have with significant oncampus and off-campus benefits. On the other hand, the team found that "the technology-enabled lifelong learning field overall is complex, highly competitive, rapidly evolving, and often not profitable" and that such a program would not be sustainable at MIT if the audience were limited to alumni. A viable program would require at least 25,000 participants - a model market would include 25 corporations, 5 professional organizations, and 5,000 alumni, and produce about 100 modules per year. The financial models predicted that the effort would require an up-front investment of $\$ 2 \mathrm{M}$ and that the program would break even in about five years. The report recommended establishing a new centralized organization to implement and manage an initiative of this scale. At the same time it cautioned that there were significant policy issues around faculty intellectual property and revenue sharing that would need to be addressed, noting that such a project would place MIT in a non-traditional business where it had or no existing capabilities.

The summer team had met its charter. But as September drew to a close and the final report was being prepared, some of the MIT members of the team, began to worry that after all the work, the results were uninspiring. After all, even if MIT were to successfully implement the Knowledge Updates plan - something that was far from certain - the outcome would not make a large difference in terms of MIT influence or leadership.

Over the summer, while discussing alternative business models, the team had briefly raised the possibility of distributing not-for-profit educational materials on the Web, but without pursuing any concrete plans. As Yue struggled to pull together the final report, he decided to resurrect this idea and include it with the committee recommendations. The Booz Allen team was cautious: the existing recommendations were the result of painstaking research and analysis, and here was a major, counterintuitive, last-minute addition, based on no analysis at all. Nevertheless, they agreed to include it in the report, and the team hurriedly crafted some rationales for the initiative: the enhancement of MIT's leadership and reputation, the possible contribution to other Educational Technology Council initiatives, the benefits to on-campus intellectual life, and the recognition that "MIT is really about dissemination of knowledge." The team also noted that the existence of the free material could give MIT a competitive advantage in pursuing Knowledge Updates. 
The summer team's final report had a split personality. The recommendations and conclusions about Knowledge Updates were carefully crafted, complete with charts and financial models and supported by attachments. And then there was a final, tentative addition, which appeared almost as an afterthought, with only hastily crafted justifications and no analysis or attachments whatsoever:

A revolutionary notion of OpenCourseware@MIT could radically alter the entire lifelong learning and distance learning field and MIT's role in it and should be seriously considered. ${ }^{11}$
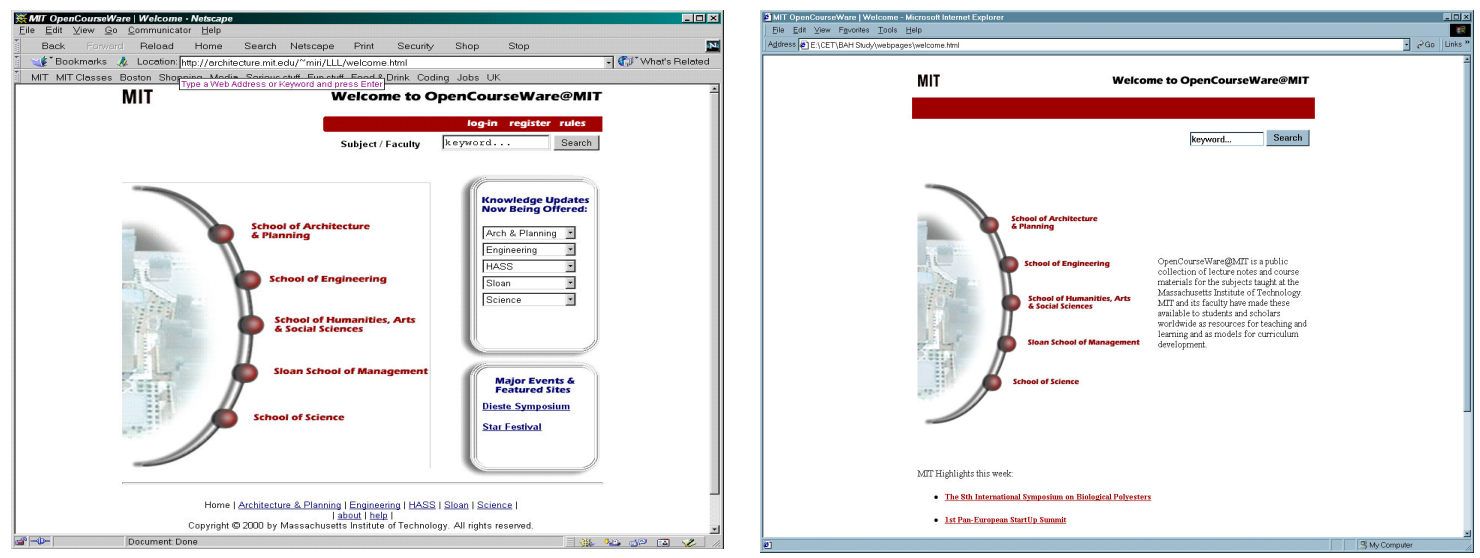

Figure 1

Left: Initial conception of an MIT OpenCourseWare home page, showing the potential for OCW to attract people to knowledge updates offerings. (From the report of the Lifelong Learning Study Group to the MIT Academic Council, October 17, 2000.) Right: The MIT OpenCourseWare home page used in presentations to faculty and to foundations beginning in November 2000 was derived from the original conception, but Knowledge Updates had been removed.

This section of the report concluded with a mock-up of a possible OpenCourseWare home page that had two major sections. One half of the page held links to the free courses available from each of MIT's five schools. The other half, was labeled "Knowledge Updates now being offered." The overall message was that the free material could attract people to the (non-free) Knowledge Updates. But as the plan for OpenCourseWare took shape, the connection to a for-profit venture became increasingly tenuous. By the time OpenCourseWare was presented to the faculty or to foundations for discussion a month later, the Knowledge Updates had disappeared from the envisioned home page. (See Figure 1.)

Despite the lack of analysis and the tentative nature of the recommendation for OpenCourseWare, the administration reacted to the concept with enthusiasm. MIT President Charles Vest contacted William Bowen, President of the Mellon Foundation who, together with program officer Ira Fuchs, were receptive to the idea and asked to hear more. The week before Thanksgiving, an MIT delegation met with Bowen and

\footnotetext{
11 “Lifelong Learning Study, Summer 2000” report to the MIT Academic Council Deans' Committee, October 17, 2000.
} 
Fuchs at the Mellon Foundation office in Princeton, bringing with them a hastily-crafted prototype of an envisioned OpenCourseWare site with materials from five courses. Yue presented careful financial projections of expected costs for the project, which he had developed using the modeling tools from the summer study. According to the financial projections, an OpenCourseWare project could publish essentially all MIT undergraduate and graduate courses over a period of 8 years at a total eight-year cost of $\$ 93$ million, and a steady-state annual cost of $\$ 6.2$ million (not counting inflation). Bowen and Fuchs were interested in hearing more, and they also offered to also approach Paul Brest, President of the Hewlett Foundation, to discuss joint Mellon-Hewlett funding.

Three weeks later, MIT representatives met at Mellon headquarters in New York with Bowen, Fuchs, Brest, and Brest's wife Iris - an attorney with expertise in intellectual property. Both foundations were impressed at how MIT had taken care in working with McKinsey and Booz Allen while other universities had been jumping into distance education ventures without even developing business models - although Bowen and Levin, who had carefully studied Lifelong Learning report, criticized the monetary projections for Knowledge Updates as over-optimistic. The Brests advised that the intellectual property issues of dealing with third-party material in OpenCourseWare would prove to be "interesting." The outcome of the meeting was an assurance that both foundations, whose boards would make funding decisions in the spring, would consider an OpenCourseWare proposal from MIT very seriously.

\section{Approval (Winter 2000)}

Positive signals from the foundations notwithstanding, Chancellor Bacow cautioned that MIT could not announce this initiative before having extensive discussions within the community. Following his advice, the OpenCourseWare planners distributed a slide presentation together with a "frequently asked questions" memo to all academic department heads, explaining that a group of the OpenCourseWare planners would conduct individual discussions with each department during January and February, leading up to an MIT faculty meeting vote at the end of February.

The associated FAQ provided basic information, making it clear that the participation would be voluntary, and that copyright of the materials would continue to rest with the authors, rather than with MIT. The very first question addressed in the FAQ revealed the planning group's sensitivity towards any perceived conflict between OCW and the paramount importance of MIT residential education:

\section{How does OCW support and enhance MIT undergraduate education?}

- OCW is based on principles that are consistent with MIT's mission of the highest quality residential based undergraduate and graduate education.

- OCW will provide support for faculty time as well as TA's and production staff to produce the materials.

- OCW will provide a vehicle for institute-wide modernization of MIT education using educational technology. 
- OCW will enhance on-campus intellectual life: serve as a common repository and channel of intellectual activity; stimulate interdisciplinary research

- OCW creates opportunities for major innovations of on-campus education. $^{12}$

The ensuing meetings with 33 individual departments and major administrative units were - to the relief of the anxious planning group - reassuringly positive. The most widespread reaction was that OCW would help with course content modernization, providing resources and unburdening faculty from technical production chores. There was also recognition that MIT faculty were putting course materials on the Web anyway, and that doing this on a large scale would be more efficient in terms of technology and in addressing policy issues. And there was a strong positive reaction, but only from a minority, that OCW would be a way for MIT to take the moral high road and exert leadership. As a faculty attendee at one of the department meetings advised:

[You] need to sharpen the message of what this is all about. You were the one who mentioned the word "grandeur": a grand project deserves a grand idea. The grand idea here is that MIT is reminding everyone of the democratic and civilizing possibilities inherent in the information age, and our desire to fulfill those possibilities by making our information public and free. We should be quite up front about the way we are bucking the trend towards privatizing information for personal or corporate gain. ${ }^{13}$

There were also negative reactions. One recurring concern was that the resource estimates were not well developed and that the resulting effort could end up costing much more than anticipated. Another was that MIT would end up creating a cumbersome bureaucracy to implement the program. There was also a worry that the OCW materials would be low quality - it was one thing to publish textbooks that had been carefully reviewed and edited, but exposing semi-formal and unfinished lecture notes to world view might reflect badly on the reputation of faculty and of MIT. Another, less widespread criticism was that the program was not technically or pedagogically ambitious and that OCW would divert energy from more innovative educational technology efforts. And very small number of faculty expressed the strongly negative view that OCW would devalue the MIT curriculum, or deprive MIT of revenue opportunities. In the words of one comment:

The idea that this "Takes the Moral High Ground" is misguided. This initiative takes the wealth of MIT (created by hard work and toil over several generations) and devalues [it] to zero. ${ }^{14}$

\footnotetext{
12 “OpenCourseWare@mit.edu: Background information for the Faculty”, January 2001 (unpublished MIT internal memo to faculty)

${ }^{13}$ Email comment to the OCW planning group in response to a department meeting.

${ }^{14}$ Ibid.
} 
Overall, however, the faculty reaction was supportive. The discussions culminated in a general presentation at the February faculty meeting, at the end of which, President Vest

... expressed his personal opinion that MIT should take advantage of this current brief shining moment in which the web is still being used to make information available for free. The trend in higher education, he continued, is shifting towards a model of selling information. MIT could be a disruptive fore by demonstrating the importance of giving information away. He noted that in the 1960s and 70s MIT had a big impact on education, not only from textbooks that were published by the faculty, but also from the course notes, problem sets and other materials our graduates took to other institutions where they used them in their teaching. OCW, he stated, gives us another chance to make such an impact. ${ }^{15}$

At the beginning of March, the administration decided to proceed and chartered an "OCW Implementation Task Force" under Yue to create an initial organizational model, production processes, and business plan.

In the meantime, Brown, Faculty Chair Steve Lerman and Educational Technology Council co-chair Hal Abelson prepared a proposal to the Mellon and Hewlett Foundations, laying out a plan for an OpenCourseWare project that would be divided into three phases:

1. A pilot phase, running for the first 27 months of the project, during which MIT would test several production models and mount 500 subjects to show the breadth and depth of the MIT curriculum. The pilot phase would also develop a plan for reaching out the other institutions, establish guidelines for collaboration, and identify organizations and conferences to work through to encourage other universities to follow the OpenCourseWare model. The proposal to the foundations requested $\$ 11.5 \mathrm{M}$ to support this pilot phase.

2. A ramp-up phase, years 3 through 8 of the project, at the end of which the entire MIT curriculum would have been published. Outreach activities would also increase over this period. The cost of this phase would be shared between MIT and the foundations, with MIT assuming an increasing share of the cost as time when on.

3. Steady state, beginning after 8 years, where MIT would assume the full cost of continuing of OpenCourseWare.

The plan estimated that the total cost of the OpenCourseWare initiative would decrease over the ramp-up phase as the organization gained experience with more efficient production practices, and the project moved from predominantly mounting new courses, to predominantly updating existing ones. In fact, the plan anticipated that almost all

\footnotetext{
${ }^{15}$ MIT Record of the Faculty Meeting of February 21, 2001. On the Web at <https://web.mit.edu/dept/libdata/libdepts/d/archives/facmin/010221/010221.html>, visited July 11, 2006.
} 
courses would in fact have been published by the end of year 5, and that years 6 through 8 would focus on transition to steady state.

This proposal was submitted to the Mellon and Hewlett Foundations at the end of April and approved at the foundations' board meetings in June.

\section{Going live (Spring 2000)}

OpenCourseWare was publicly announced at the beginning of April 2001. The news that a top university was so deliberately bucking the trend for commercial distribution of curriculum was noteworthy enough to glean a front-page article in the New York Times: ${ }^{16}$

Other universities may be striving to market their courses to the Internet masses in hopes of dot-com wealth. But the Massachusetts Institute of Technology has chosen the opposite path: to post virtually all its course materials on the Web, free to everybody.

The announcement was the MIT news event of the spring. Between April 4 and April 6, the News Office received over 800 emails from around the world, congratulating MIT on its vision and its generosity. As one enthusiast commented:

What an extraordinary idea! As a former academic and someone who took the more traditional route to a Ph.D. in the old days, I'm simply in awe of your ambitious initiative. That it comes from a private university which could arguably maintain that it does not have the same obligation to the public as a state university is even more striking. I'm sure that while you've already considered a wealth of obstacles to your plans, many more will emerge as you try to implement it. Don't give up. From my perspective this is the most hopeful sign to emerge from academia in a long, long time.

Announcing OpenCourseWare had originally been planned to coincide with the foundations' funding approval. But as the spring of 2001 progressed, word of the proposed initiative - which, after all, was being widely discussed on campus - began to get around, and there had been inquiries from the local press. So the administration decided to engineer its own news release in a way that it could control the timing, and contacted the Times. The early announcement, as it turned out, proved beneficial, even though it was a bit of risk, since the proposal to the foundations, submitted shortly after the announcement, was able to highlight some of the enthusiastic responses.

At the end of June, Yue's OCW Implementation Task Force returned its report, recommending a structure for a new OpenCourseWare organization and proposing a production plan. In accepting the report, the administration approved the appointment of an interim project management board and a transition team that would launch the project and begin a search for an executive director. By October 2001, the transition team had produced an internal testing site illustrating materials from 30 courses, and a search for an executive director was underway. After an extensive search, the management board

\footnotetext{
16 “Auditing Classes at M.I.T., on the Web and Free,” Carey Goldberg, New York Times, April 4, 2001.
} 
finally offered this position to Anne Margulies, chief operating officer of a communications consulting firm, who had previously served as assistant provost and executive director for Information Systems at Harvard.

Margulies arrived at MIT in May 2002 with the daunting charter to build a new organization and a new production system, to mount a 50-course demonstration site by September 2002, and to complete the proposal's pilot phase with 500 courses published by September 2003. The 500-course deadline had teeth: continued foundation funding for the production phase would be contingent on contingent meeting it.

\section{Ramp-up (2002-2006)}

The organization Margulies created met both deadlines with a success beyond what even the original OpenCourseWare planners had expected. The 50-course launch in September 2002 drew messages from around the world with praise so effusive as to verge on embarrassment, with comments like "it's the Big Bang in the Knowledge Universe," and "one of the few beacons of enlightened thinking in an age where the darkness of oppression and proprietary small-mindedness threatens the liberties of free thinkers."

One result of the publicity was the emergence of significant international interest in OpenCourseWare, with offers to translate the MIT material into other languages. The spring 2001 OpenCourseWare funding proposal had described a pilot phase that focused almost entirely on MIT, anticipating only to develop a plan for reaching out to other institutions, to establish guidelines for collaboration, and to create a collection of working groups to discuss implementation of the OpenCourseWare concept. But with the encouragement of the foundations, OpenCourseWare concluded agreements for Spanish and Portuguese translations with Universia, a consortium of 900 universities in Spain, Portugal, and Latin America; for Simplified Chinese translations with "China Open Resources for Education" (CORE), a consortium of leading universities in China that was formed largely around the opportunity to translate the MIT material; and for traditional Chinese with "Opensource OpenCourseWare Prototype System" (OOPS), a volunteer organization based in Taiwan. ${ }^{17}$ The formal announcement that OpenCourseWare had met its September, 2003, deadline for 500 courses was in fact made by Margulies at CORE's inaugural meeting in Beijing on September 22nd , after some nervous trans-Pacific phone calls back to Cambridge verifying that the final few courses were actually in place.

Six years after the initial presentation of the OpenCourseWare concept to MIT's administration, it's remarkable how closely the project has adhered to the plan set out in the spring 2001 proposal to the foundations. As anticipated, virtually all MIT courses have been published - 1600 courses as of November 2006, with $80 \%$ of MIT faculty participating - and the production process on track to hit a "virtually all MIT courses" number of 1800 in fall 2007.

${ }^{17}$ See < http://www.universia.net/> for Universia, <http://www.core.org.cn> for CORE, and $<$ http://www.myoops.org/twocw/> for OOPS. 
OCW has met its publishing targets with costs lower than projected. The cost of the pilot phase was $\$ 6 \mathrm{M}$, not $\$ 11.5 \mathrm{M}$, leaving a surplus to be carried over in the ramp-up phase. Total costs for the first three years of ramp-up have been $\$ 18.1 \mathrm{M}$, as compared with the 2001 proposal's projections of $\$ 22.5 \mathrm{M}$. Also, as requested, the Mellon and Hewlett Foundations continued their support into the ramp-up phase, with Mellon so far contributing another $\$ 6 \mathrm{M}$ beyond its initial half of the $\$ 11.5 \mathrm{M}$, and Hewlett another \$5.9M.

The MIT OpenCourseWare web site has, as hoped, become a significant global educational resource. Fewer than half $(43 \%)$ of its visitors originate from within North America, the others coming primarily from East Asia (17\%), Western Europe (14\%), South Asia (7\%), Latin America (5\%), and Eastern Europe (4\%). Access to MIT translation partners is also substantial: in January 2007 there were 75,000 visits to the Universia translations, and a quarter-million visits each to the CORE and OOPS translation sites.

Beyond MIT course material, OpenCourseWare has outperformed expectations in its outreach activities. The 2001 proposal spoke in terms of assisting other interested institutions in creating their own versions of OpenCourseWare, by sharing MIT's experience and by creating working groups. The OCW Consortium, only two years old, is already describing itself as a "movement," and although the non-MIT participants are just getting started, MIT material comprises just half of the 3000 courses currently available.

\section{Challenges of steady state (2007)}

Six years into the project, according to the plan presented to the foundations in 2001 is the time for OpenCourseWare to begin its transition to a steady state where MIT will assume the full cost of the operation. It's now, with OCW successfully launched and in full production, that the next major challenge arises.

The original 2001 plan projected the cost of OCW in year 5 be $\$ 7.4 \mathrm{M}$, with $\$ 1.1 \mathrm{M}$ coming from general budget (i.e., MIT's recurring internal support for core operations, outside of any outside special funding), and with the remaining coming from external fundraising. Actual year 5 costs were $\$ 5.6 \mathrm{M}$, with general budget providing $\$ 1.1 \mathrm{M}$ as anticipated. The original plan projected that general budget support would rise during the three-year transition, reaching $\$ 1.7 \mathrm{M}$ in year 8 .

A proposal recently put before the MIT administration anticipated a steady-state annual cost for OCW of around $\$ 4 \mathrm{M}$, with about half coming from general budget. While that seems in line with the 2001 plan, the question is whether - six, seven, eight years later, and on into the future - MIT will accept the internal cost and whether the additional external funding can materialize.

There seem to be three strategies for sustainability. The first is to change the technology and architecture so as to reduce the cost of creating OpenCourseWare material, by integrating OCW production with the web sites that faculty normally provide for their students with the aid of learning management systems (LMS). The idea is that faculty will produce these LMS sites as part of ordinary instruction, so the incremental 
cost of generating the OCW site should be marginal - perhaps it could even be done automatically if the technology of the LMS and the technology of the OCW publishing operation were suitably matched. The original OCW planners discussed this option in 2001 and decided against it, concluding that the technology wasn't ready, and that concern about integration with an LMS could complicate the job of the nascent OCW operation.

Five years later, with technology more mature (particularly technology around web services and interoperability) it seems promising to return to this idea. MIT has already implemented the interoperability and workflow architecture between OCW and the Institute's DSpace digital repository to enable long-term archiving of OCW course sites. ${ }^{18}$ Integration with an LMS seems more problematic, not the least because producing LMS materials suitable for automatic transformation by an OCW production process might place an unacceptable burden on faculty. In addition, the copyright status of materials incorporated into LCS sites must be checked before publication in a global resource like OCW, and this presents challenges for automation. As the Brests predicted in 2000, dealing with third-party materials in OCW would be "interesting."

Nevertheless, there have been small-scale demonstrations by OpenCourseWare Consortium members of auto-generating OCW sites from LMS sites, and MIT OCW itself is conducting some pilot evaluations in collaboration with University of Michigan. Whether such a system really does lower the cost of a full-scale OCW operation remains to be demonstrated.

A second approach to sustainability is for OCW to take on more of an external agenda, expanding MIT's activities in the Consortium or providing additional services. There have already been experiments hosting on-line discussion groups linked to individual courses, and creating enhancements to the OCW material, including automatic generation of transcripts for audio and video lectures so that they can be indexed and searched, and links to experimental automated tutoring systems and even remote access to laboratory instruments. These activities are attractive because they increase OCW's value as a global resources, and also because they provide opportunities for additional foundation support. On the other hand, this expansion of activities would likely increase the cost of the OCW operation. If the additional funding to support these new initiatives is only temporary (as is typically the case with foundation grants) this could make the challenge of long-term sustainability more difficult.

A third approach is for OCW to expand and solidify its contributions to MIT core educational functions, thereby justifying significant permanent support from the general budget. OCW already provides value to MIT by enhancing the Institute's reputation for leadership. It also provides more direct benefits. Of 600,000 monthly visits to the MIT OCW web site in September 2006, 25,000 originated from within MIT itself, a substantial number, considering that there are only about 13,000 students and faculty at MIT, and only 23,000 MIT network users in total. MIT students and their faculty advisors are regularly using OCW for previewing and selecting subjects and courses of

\footnotetext{
${ }^{18}$ See William Reilly, Robert Wolfe, and MacKenzie Smith, “MIT's CWSpace project: packaging metadata for archiving educational content in DSpace,” Intnl. J. Digital Libraries, 6(2), 2006, pp: 139-147.
} 
study, and also for reviewing courses they've previously taken: $60 \%$ of faculty and $70 \%$ of students report that they make at least some use of OCW. There's also evidence that OCW is serving as a positive factor in student admissions by giving applicants a preview of what they could be studying if they matriculated at MIT.

OCW could strengthen its current role in helping MIT students review material from their previous course. More generally it could enhance the capabilities it provides for students and faculty to use materials from courses they are not currently participating in, and it could work with faculty in using this to promote coherence across the curriculum. OCW could expand its content to include the information about departmental degree programs and other educational activities that is presently contained in the MIT catalog. Going further, one could imagine OCW evolving to become the primary locus of web-based information about MIT's educational programs, both internally and externally, thus fulfilling the promise held out to faculty in the January 2001 FAQ, that "OCW will enhance on-campus intellectual life: serve as a common repository and channel of intellectual activity; stimulate interdisciplinary research."

Achieving sustainability for OCW will in all likelihood require elements of all three approaches: cost reduction, new development to attract additional funding, and an enhanced core MIT role. This would be challenging line to walk, since it means that the OCW organization would require elements both of an outwardly looking research and development organization and an internally looking service organization. But perhaps such a balance of external and internal charter is precisely what will become increasingly characteristic of university information technology in the Internet age.

OCW emerged at the height of the dot-com bubble, a time when the vision of universities exploiting the Internet to market educational content had captured academia's imagination. Indeed, as recounted above, the strategic effort that produced OCW emerged from that same vision, transforming itself into something different only after a skeptical analysis of those dot-com dreams. That skepticism appears to have been justified. Of all the university commercial ventures studied by the McKinsey-MIT team in early 2000, eCornell is the only one to have survived the dot-com bust. ${ }^{19}$

And what of OCW? Can universities realize enough benefit in providing open educational resources that they can maintain them permanently, even through times of tight budgets? Are there sustainable institutional models for openness? The answer speaks to the very nature of the university as an institution in the time of the Internet, and it matters deeply for the future of academia in the Information Age.

\footnotetext{
${ }^{19}$ The Caliber Learning Network and Pensare both filed for bankruptcy in 2001, UNext came under financial pressure that same year, renegotiated its university agreements and morphed into Cardean University, which offers online graduate and undergraduate programs. Columbia's Fathom consortium, which at one point had 14 partners and won awards in 2002 and 2003, closed down in 2003. Princeton withdrew from the POSY Alliance, which had been launched February 2000, only two year later, in Nobember 2001. The remaining Oxford-Stanford-Yale venture carried on but struggled to attract enough students to meet its costs, and eventually closed its doors in March 2006. ("Elite Universities End Venture to Provide Noncredit Online Courses," Andrea Foster, Chronicle of Higher Education, March 23, 2006.)
} 


\section{Postscript on Knowledge Updates (2001-2005)}

While MIT administration was enthusiastic about the OpenCourseWare in the October 2000 Lifelong Learning report, the response to the same report's recommendation on Knowledge Updates was more tempered. Perhaps Yue's original concern that a Knowledge Updates initiative would be relatively uninspiring was justified, or perhaps the preparations for OpenCourseWare monopolized the energy available to devote to distance education. In any event, the Educational Technology Council played only a minor role in continued Knowledge Update planning, and left it to the School of Engineering and the Sloan School of Management to prepare a detailed program plan. This was presented to the Provost in December 2002, but the Provost was skeptical and decided not to allocate central MIT funding to the effort. The Sloan School then withdrew, also declining to allocate their own funds. The School of Engineering continued the effort alone and, aided by a grant from the Lord Foundation, developed a prototype Knowledge Update module featuring the work of Prof. Robert Langer on localized drug therapy. This led to the approval by the School of Engineering of threeyear pilot project beginning in May 2003.

The Engineering Knowledge Updates project produced 20 modules in the area of life sciences between May 2003 and September 2005. Each module - the topics offered included Systems Biology, Microfluidic Devices, and Electronic Control of Biomolecules - consisted of 30 to 100 web pages with a topic overview, references, and information on key companies and people, together with 5 to 20 minutes of video presentation. Modules sold for between $\$ 75$ and $\$ 450$ depending on the length. Production costs for a module were between $\$ 15,000$ and $\$ 20,000$, which was right in line with the analysis of the Lifelong Learning summer 2000 study. But the summer study's market projections proved to be wildly optimistic: the initial offering between October 2005 and January 2006 garnered only a few dozen requests for further information and only about a dozen sales.

Perhaps MIT could have done a more aggressive marketing effort for Knowledge Updates. But the real factor, according to a follow-up marketing analysis conducted by the School of Engineering, was that the world had changed immensely between 2000 and 2005. Few survey respondents were willing to pay $\$ 450$ for these kinds of materials, and most said that, of different types of educational products and services, they were most satisfied with free Web-based resources. In 2000, the dot-com conventional wisdom held that selling educational content on the Web could be a gold mine. By 2005, collections of quality educational content were becoming increasingly available for free, including through efforts like OpenCourseWare.

\section{Acknowledgements}

The following members of the MIT community graciously provided background information for this essay: Alex d'Arbeloff, Jesús del Alamo, Steve Carson, Andrew Eisenmann, Morton Flemings, Eric Grimson, Judson Harward, Anne Margulies, Jennifer Stine, Diana Strange, John Vandersande, and Dick Yue 